\title{
BMJ Open Sedation strategy and ICU delirium: a multicentre, population-based propensity score-matched cohort study
}

Colin Casault (D) , Andrea Soo, ${ }^{1}$ Chel Hee Lee, ${ }^{2}$ Philippe Couillard, ${ }^{1}$ Daniel Niven, ${ }^{1}$ Tom Stelfox, ${ }^{2}$ Kirsten Fiest (iD ${ }^{1}$

To cite: Casault C, Soo A, Lee $\mathrm{CH}$, et al. Sedation strategy and ICU delirium: a multicentre, population-based propensity score-matched cohort study. BMJ Open 2021;11:e045087. doi:10.1136/ bmjopen-2020-045087

- Prepublication history and additional online supplemental material for this paper are available online. To view these files, please visit the journal online. To view these files, please visit the journal online (http://dx.doi.org/10.1136/ bmjopen-2020-045087).

Received 22 September 2020 Accepted 06 July 2021
A) Check for updates

(C) Author(s) (or their employer(s)) 2021. Re-use permitted under CC BY-NC. No commercial re-use. See rights and permissions. Published by BMJ.

${ }^{1}$ Department of Critical Care Medicine, University of Calgary Cumming School of Medicine, Calgary, Alberta, Canada

${ }^{2}$ Department of Critical Care, University of Calgary Cumming School of Medicine, Calgary, Alberta, Canada

Correspondence to Dr Colin Casault; casaultc@gmail.com

\section{ABSTRACT}

Objectives We examined the relationship between dominant sedation strategy, risk of delirium and patient-centred outcomes in adults admitted to intensive care units (ICUs). Design Retrospective propensity-matched cohort study. Setting Mechanically ventilated adults ( $\geq 18$ years) admitted to four Canadian hospital medical/surgical ICUs from 2014 to 2016 in Calgary, Alberta, Canada.

Participants 2837 mechanically ventilated adults $(\geq 18$ years) requiring admission to a medical/surgical ICU were evaluated for the relationship between sedation strategy and delirium.

Interventions None.

Primary and secondary outcome measures The primary exposure was dominant sedation strategy, defined as the sedative infusion, including midazolam, propofol or fentanyl, with the longest duration before the first delirium assessment. The primary outcome was 'ever delirium' identified using the Intensive Care Delirium Screening Checklist. Secondary outcomes included mortality, length of stay (LOS), ventilation duration and days with delirium. The cohort was analysed in two propensity score (patient characteristics and therapies received) matched cohorts (propofol vs fentanyl and propofol vs midazolam).

Results 2837 patients $(60.7 \%$ male; median age 57 years (IQR 43-68)) were considered for propensity matching. In propensity score-matched cohorts(propofol vs midazolam, $n=712$; propofol vs fentanyl, $n=1732$ ), the odds of delirium were significantly higher with midazolam (OR $1.46(95 \% \mathrm{Cl}$ 1.06 to 2.00)) and fentanyl (OR 1.22 (95\% Cl 1.00 to 1.48)) compared with propofol dominant sedation strategies. Dominant sedation strategy with midazolam and fentanyl were associated with a longer duration of ventilation compared with propofol. Fentanyl was also associated with increased ICU mortality (OR 1.50, 95\% Cl 1.07 to 2.12)) ICU and hospital LOS compared with a propofol dominant sedation strategy.

Conclusions We identified a novel association between fentanyl dominant sedation strategies and an increased risk of delirium, a composite outcome of delirium or death, duration of mechanical ventilation, ICU LOS and hospital LOS. Midazolam dominant sedation strategies were associated with increased delirium risk and mechanical ventilation duration.

\section{INTRODUCTION}

Delirium in critically ill patients is an acute confusional state marked by severe
Strengths and limitations of this study

- We examine the effects of midazolam and fentanyl sedation strategies on delirium and patient-centred outcomes using a large cohort of general intensive care patients.

- To reduce bias, we used a propensity score matching process on an extensive database.

- One fundamental limitation is secondary to the concurrent use of multiple overlapping sedation strategies, which may impact the results.

- Based on the limitations and the nature of cohort studies, this study as hypothesis generating.

disorganisation of cognition, fluctuating course, attentional deficit and a disturbance of awareness. ${ }^{1}$ Older age, severity of illness, presence of mechanical ventilation, coma,and sedative medications place over $50 \%$ of intensive care unit (ICU) patients at risk for developing delirium. ${ }^{2-6}$ Delirium in the ICU is common and may prolong hospital stay, increase mortality risk and contribute to long-term cognitive impairment. ${ }^{78}$ With a burgeoning elderly population, ICU admission requiring mechanical ventilation is estimated to increase by $80 \%$ by 2026 ; therefore, understanding potential contributors to delirium is paramount. ${ }^{910}$

Oversedation in the ICU, with benzodiazepines, in particular, may be harmful. ${ }^{11}{ }^{12}$ Prospective cohortand randomised controlled trials support shorter durations of mechanical ventilation, more rapid awakening with propofol or dexmedetomidine than midazolam. ${ }^{13-17}$ Similarly, a population-based study by Lonardo et al demonstrated higher mortality, longer duration of mechanical ventilation and longer ICU length of stay (LOS) in patients managed with benzodiazepines compared with propofol. ${ }^{11}$ Lonardo et al postulated midazolam's mortality effect might be due to increased rates of delirium. Delirium is associated with mortality, and 
some evidence supports patients treated with benzodiazepines may demonstrate higher rates of delirium in the ICU. ${ }^{8131819}$ However, the association between benzodiazepines and delirium is inconsistent. ${ }^{6}$

Sedation strategies often employ both a sedative, like propofol and an analgesic, like fentanyl, simultaneously to achieve the desired effect. However, studies evaluating the clinical effects of these sedation strategies are lacking. Additional research is necessary to understand the effects of sedation strategies on delirium, hospital LOS and survival outcomes. Our study examined the relationship between dominant sedation strategy (continuously infused propofol, fentanyl and/or midazolam), delirium and important patient-centred outcomes, in a multicentre population-based sample of mechanically ventilated adults admitted to ICU.

\section{METHODS}

This retrospective cohort study was reported in compliance with the Strengthening the Reporting of Observational Studies in Epidemiology statement ${ }^{20}$ and approved by the conjoint health research ethics board at the University of Calgary (REB17-0389).

\section{Patient and public involvement statement}

Neither patients, nor the public were not involved in the design, collection, compilation or completion of this research study.

\section{Study setting and population}

We identified consecutive mechanical ventilated adults ( $\geq 18$ years) admitted to four medical-surgical ICUs in Calgary, Alberta, Canada between 1 January 2014 and 30 June 2016. Patients were excluded if:

1. Their ICU electronic health data did not link to an appropriate inpatient (hospital) admission.

2. They did not have any ICU admissions with at least 1 Intensive Care Delirium Screening Checklist (ICDSC) assessment (details described in the Outcome measures section).

3. They were non-Alberta residents (to allow for mortality outcome follow-up post hospital discharge).

4. They did not receive at least one continuous infusion of midazolam, propofol or fentanyl prior to the first ICDSC assessment.

5. They were never invasively ventilated during their ICU stay.

6 . They did not have a single dominant continuous infusion prior to the first ICDSC assessment (see definition of dominant sedation strategy in the Exposure measure section below for further detail).

If the patient was readmitted to ICU more than once during the study period, then only the first admission with at least 1 ICDSC assessment was used. The ICUs are staffed by accredited intensive care physicians which provide mechanical ventilation, vasoactive medications and invasive monitoring.

\section{Data sources}

Study data were derived from three electronic databases. ${ }^{21-23}$ eCritical Alberta, a database and electronic medical record, that prospectively captures detailed clinical and demographic information. ${ }^{22}$ The discharge abstract database captures data on all hospitalised patients, including admission date, discharge, survival status and up to 25 diagnostic codes from the International Classification of Diseases, 10th revision, Canadian enhancement. Out of hospital deaths were obtained from Alberta Vital Statistics, which captures all deaths occurring in Alberta. Data from Alberta Vital Statistics was available up to 30 December 2017, which provided at least 18 months of follow-up from the ICU admission date.

\section{Exposures and definitions}

The main study exposure was dominant sedation strategy prior to the first ICDSC assessment. A sedation strategy was defined as a continuous analgo-sedative infusion limited to midazolam, fentanyl, and propofol. Infusions were selected based on a screening survey which demonstrated small populations using alternative sedation strategies. There were seven possible combinations for the sedation strategy prior to the first ICDSC assessment: (1) propofol only, (2) fentanyl only, (3) midazolam only, (4) propofol and fentanyl, (5) propofol and midazolam, (6) fentanyl and midazolam and (7) all three agents. A high number of patients received more than one agent, therefore, we classified patients into a dominant sedation strategy, defined as the longest continuous duration of infusion prior to the first ICDSC assessment, which consists of three categories for the primary analyses. For example, if fentanyl was provided for the longest duration, fentanyl was considered the dominant sedation strategy. It is possible the patient could have received propofol or midazolam (or neither) for a duration less than fentanyl. If the patient received two agents for the same duration, the patient was excluded as no strategy was dominant. As sensitivity analyses, all seven possible combinations of the sedation strategy used prior to the first ICDSC assessment were considered.

\section{Outcome measures}

The primary outcome was categorised as 'ever/never delirium' during ICU admission compatible with previously established delirium outcome measures. ${ }^{7}$ All ICU patients with a Richmond Agitation Sedation Scale


ICDSC tool ${ }^{25}$ and received a protocolised sedation awakening trial. The ICDSC is a validated delirium assessment tool. ${ }^{25}$ Ever delirium patients were those with an ICDSC score $\geq 4$; never delirium were those with an ICDSC score $<4$. Total number of days with an ICDSC score $\geq 4$ defined delirium duration. Duration of delirium (days) was examined in secondary analyses.

Delirium motor subtypes were identified using the RASS, based on previously published criteria, ${ }^{18}$ and associated positive ICDSC score of $\geq 4$. The scale is scored 
from -5 points (unarousable) to 0 points $(\mathrm{calm})$ to +4 points (combative), where scores between -3 to 0 indicate hypoactive delirium, scores between 1 to 3 indicate hyperactive delirium, and scores that fluctuate between hypoactive and hyperactive indicate mixed delirium. All ICDSC scores $\geq 4$ were linked to the closest RASS score within 4 hours of charting. If there was no RASS score documented within 4 hours of the ICDSC score, the subtype was considered 'unable to be classified'. If there was a RASS score within 4 hours of the ICDSC score but the RASS was -5 to -4 or +4 , the subtype was considered 'unable to be assessed'. If at least one assessment indicated hypoactive delirium and at least one assessment indicated hyperactive delirium the sub-type was considered mixed for that specific patient.

Secondary outcomes were mortality in the ICU and hospital, duration of mechanical ventilation, and ICU and hospital lengths of stay (LOS). Patient mortality was also reported at 30 days and 1 year. Duration of invasive mechanical ventilation was defined as the time a patient required the use of invasive ventilator.

\section{Statistical analysis}

Baseline characteristics were summarised using median with IQR and frequency with percent and compared between sedation strategies using $\chi^{2}$ tests and KruskalWallis rank sum tests, as appropriate. For the primary outcome analysis, logistic regression was used to assess the association between dominant sedation strategy (propofol vs midazolam vs fentanyl) and risk of developing delirium. The relationship between dominant sedation strategy and delirium duration was analysed using negative binomial models. The relationship between dominant sedation strategy and mortality outcomes were analysed using logistic regression models. The relationship between dominant sedation strategy and LOS outcomes (ICU and hospital) were analysed using linear regression models with a log-transformation of ICU LOS and hospital LOS. Primary analyses for all outcomes were based on forming two propensity score-matched cohorts: (1) propofol versus fentanyl and (2) propofol versus midazolam.

The study team considered the following prior to matching including, all measured baseline covariates, all baseline covariates that are associated with treatment assignment (eg, sedation strategy), all baseline covariates that affect the outcome (ie, potential confounders) or all covariates that affect both treatment assignment and outcome (ie, true confounders). Therefore, age, sex, reason for admission, admission acute physiologic assessment and chronic health evaluation II score(APACHE II), sequential organ failure assessment(SOFA), the Charlson Comorbidity $\operatorname{Index}(0,1,2+)$, use of vasoactives and renal replacement represented covariates which affected the outcome variables and therefore were controlled to ensure patient severity and medical issues did not confound the outcome of the treatment assignment.

The cohorts were formed based on 1:1 nearestneighbour matching without replacement using the logit of the propensity score and specified calliper width equal to 0.2 of the SD of the logit of the propensity score. ${ }^{26}$ Sensitivity analyses were based on the full cohort with models adjusted a priori for the same patient characteristics used in the propensity scores. The above analyses were repeated for the 7-category sedation strategy prior to the first ICDSC assessment. For these analyses, we formed six pairwise propensity score-matched cohorts similar to the primary analyses, matching with patients on propofol only for each of the other 6 categories of sedation strategy prior to the first ICDSC assessment. A two-sided $\mathrm{p}<0.05$ was considered statistically significant. Analyses were conducted in R, V.3.5.1. ${ }^{27}$ Propensity score matching was performed using the R package 'MatchIt', V.3.0.2. Additionally, to control for the competing effects of delirium and death, a sensitivity analysis of a composite endpoint of delirium or death was calculated.

\section{RESULTS}

There were 2837 patients in the study cohort (figure 1), which included 1412 patients $(49.8 \%$ ) receiving a propofol dominant strategy, 356 patients $(12.5 \%)$ receiving a midazolam dominant strategy and 1069 patients (37.7\%) receiving a fentanyl dominant strategy. For those receiving propofol dominant sedation, it was common to receive a single agent of only propofol (62.8\%). While among those receiving fentanyl and midazolam dominant sedation strategies, single agent use was less common with $14.8 \%$ and $34.8 \%$ only receiving a single agent, respectively. Most patients were male $(60.7 \%)$ with a median age of 57 (IQR 43-68) years and admitted for a medical reason $(50.4 \%)$. The median Charlson Comorbidity Score was 1 (IQR 0-2), admission SOFA score 7 (IQR 4-9) and admission APACHE II score 19 (IQR 14-25). Patients who received a midazolam dominant sedation strategy were more likely admitted for medical reasons (72.8\%) and had higher Charlson Comorbidity Scores, admission SOFA scores and admission APACHE II scores than those receiving propofol and fentanyl dominant sedation strategies. Patients receiving midazolam dominant strategies were also more likely to receive vasoactive medications (68.8\%) compared with those predominantly receiving propofol $(45.3 \%)$ and fentanyl dominant sedation strategies $(64.5 \%)$ (table 1$)$.

Due to missing patient characteristics for five patients $(0.2 \%)$, propensity scores were calculated for 1409 patients receiving propofol dominant strategies, 1067 patients receiving fentanyl dominant sedation strategies and 356 patients receiving midazolam dominant sedation strategies. Of the patients receiving fentanyl dominant sedation strategies, $201(18.8 \%)$ could not be matched to a patient receiving propofol dominant sedation strategies within the specified calliper width of 0.2 ; therefore, this resulted in a matched cohort for propofol and fentanyl of 1732 patients. Of the patients receiving midazolam dominant sedation strategies, all 356 patients could be matched to a patient receiving propofol dominant 


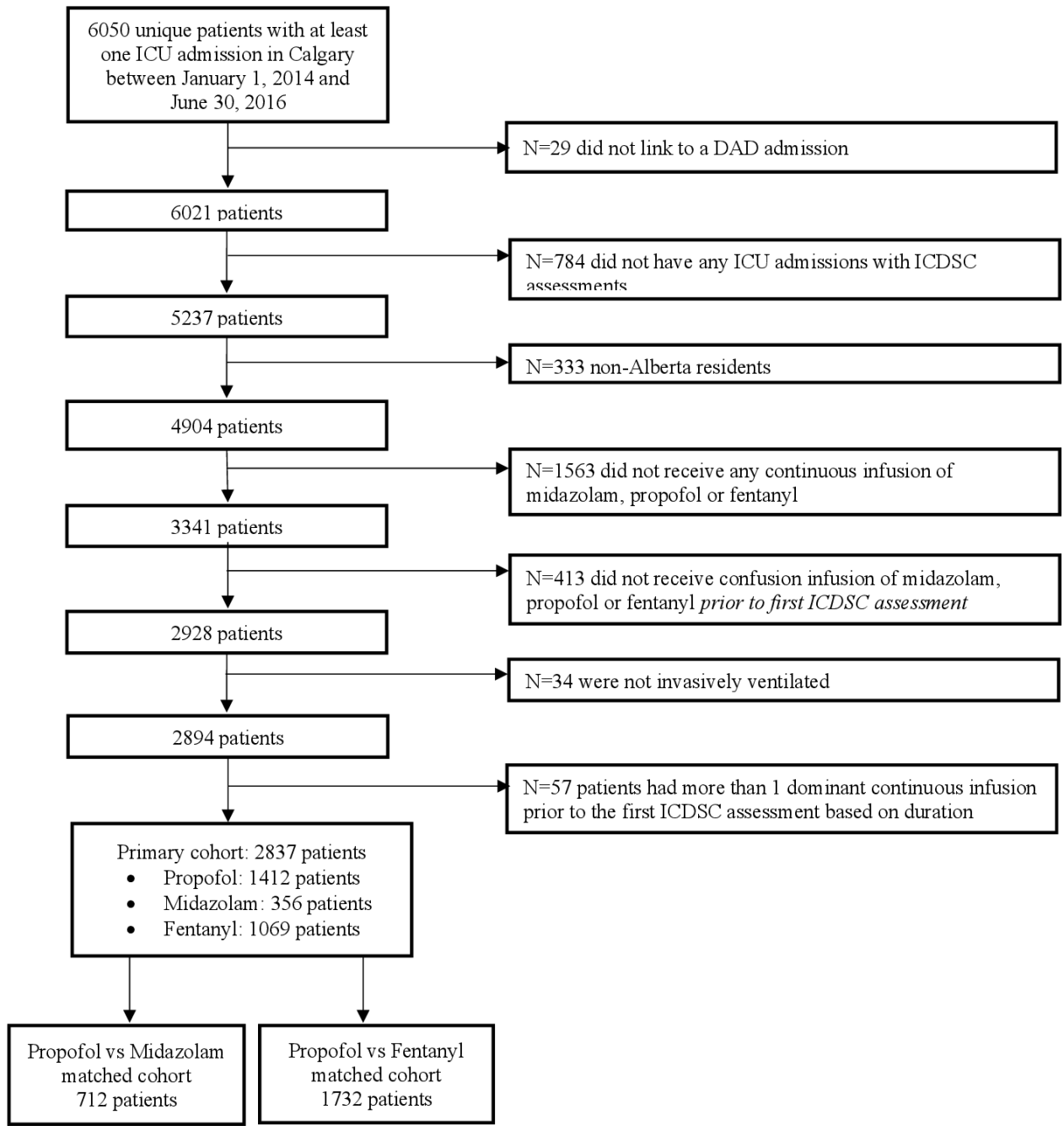

Figure 1 Cohort diagram. DAD, discharge abstract database; ICDSC, Intensive Care Delirium Screening Checklist; ICU, intensive care unit.

sedation strategies; therefore, this resulted in a matched cohort for patients with propofol and midazolam dominant sedation strategies of 712 patients. After matching, the baseline characteristics were balanced (table 1). The median time from admission to first ICDSC in hours were similar between the propofol (median time $=17.1$ hours $(\mathrm{IQR}=8.5-34.7))$, midazolam $(($ median time $=17.6$ hours $(\mathrm{IQR}=8.8-41.2))$ and fentanyl (median time $=16.5$ hours (8.8-35.4) dominant strategies. Additionally, the median number of ICDSC assessments per ICU day was similar for propofol (1.4 (IQR=1.0-1.8), fentanyl (1.4 (IQR $1.0-1.8$ ), midazolam (1.3 (IQR 1.0-1.7) dominant sedation strategies.

In the propensity score-matched cohorts, there was a statistically significant association between delirium and midazolam dominant(OR 1.46 (95\% CI 1.06 to 2.00); $\mathrm{p}=0.02)$ as well as fentanyl dominant (OR 1.22 (95\% CI 1.00 to 1.48$) ; \mathrm{p}=0.05$ ) sedation strategies compared with propofol dominant sedation strategies (figure 2). To control for the effects of death on delirium rates, a sensitivity analysis of the matched cohort was performed using a composite outcome of delirium or death. A statistically significant association between the composite outcome of delirium and death with midazolam dominant (OR $1.53,95 \%$ CI 1.10 to 2.12 ; $\mathrm{p}=0.011$ ) and fentanyl dominant (OR 1.27, 95\% CI 1.04 to $1.55 ; \mathrm{p}=0.020$ ) strategies was observed, however, not for propofol dominant strategies. Sensitivity analyses based on the seven-category sedation strategy prior to the first ICDSC assessment showed an increased odds of delirium for those on more than one agent compared with those on propofol only (table 2). Among those who ever experienced delirium, the distribution of delirium subtypes was similar between dominant sedation strategies (table 3). Based on the propensity score-matched cohorts, a fentanyl dominant sedation strategy was associated with longer duration of mechanical ventilation, longer ICU and hospital LOS and more delirium days compared with a propofol dominant sedation strategy, while a midazolam dominant sedation strategy was associated with a longer duration of mechanical ventilation compared with a propofol dominant sedation strategy(figure 3). Sensitivity analyses of the secondary outcomes and cohort characteristics based on the seven-category sedation strategy can be found in 
Table 1 Baseline characteristics

\section{Overall cohort}

\section{Dominant sedation strategy matched cohorts}

\section{Propofol versus midazolam Propofol versus fentanyl} matched cohort

\begin{tabular}{|c|c|c|c|c|c|c|c|}
\hline & \multirow[b]{2}{*}{$\begin{array}{l}\text { Propofol } \\
(n=1412)\end{array}$} & \multirow[b]{2}{*}{$\begin{array}{l}\text { Fentanyl } \\
(\mathrm{n}=1069)\end{array}$} & \multirow[b]{2}{*}{$\begin{array}{l}\text { Midazolam } \\
(\mathrm{n}=356)\end{array}$} & & \\
\hline & & & & $\begin{array}{l}\text { Propofol } \\
(\mathrm{n}=356)\end{array}$ & $\begin{array}{l}\text { Midazolam } \\
(n=356)\end{array}$ & $\begin{array}{l}\text { Propofol } \\
(n=866)\end{array}$ & $\begin{array}{l}\text { Fentanyl } \\
(n=866)\end{array}$ \\
\hline \multicolumn{8}{|l|}{ Characteristic } \\
\hline Age, median (IQR) & $56(42-67)$ & $59(44-69)$ & $59(46-71)$ & $58(48-69)$ & $59(46-71)$ & $57(46-68)$ & $57(42-69)$ \\
\hline Male, n (\%) & $843(59.7)$ & $656(61.4)$ & $223(62.6)$ & $227(63.8)$ & $223(62.6)$ & $533(61.5)$ & $520(60.0)$ \\
\hline \multicolumn{8}{|c|}{ Admission reason, $\mathrm{n}(\%)$} \\
\hline Medical & $791(56.0)$ & $379(35.5)$ & $259(72.8)$ & $253(71.1)$ & $259(72.8)$ & 426 (49.2) & $379(43.8)$ \\
\hline Surgical & $265(18.8)$ & 405 (37.9) & $69(19.4)$ & $74(20.8)$ & 69 (19.4) & $256(29.6)$ & $248(28.6)$ \\
\hline Neurological & $245(17.4)$ & $73(6.8)$ & $19(5.3)$ & $18(5.1)$ & $19(5.3)$ & $76(8.8)$ & $73(8.4)$ \\
\hline Trauma & $109(7.7)$ & $211(19.7)$ & $9(2.5)$ & $11(3.1)$ & $9(2.5)$ & $108(12.5)$ & $166(19.2)$ \\
\hline \multicolumn{8}{|c|}{ Location admitted from } \\
\hline Emergency room & $833(59.0 \%)$ & $413(38.6 \%)$ & $190(53.4 \%)$ & $202(56.7)$ & $190(53.4)$ & $441(50.9)$ & $369(42.6)$ \\
\hline $\begin{array}{l}\text { Operating room/ } \\
\text { recovery }\end{array}$ & $278(19.7 \%)$ & $399(37.3 \%)$ & $59(16.6 \%)$ & $63(17.7)$ & $59(16.6)$ & $232(26.8)$ & $271(31.3)$ \\
\hline Hospital ward & 254 (18.0\%) & 209 (19.6\%) & $91(25.6 \%)$ & 85 (23.9) & $91(25.6)$ & $165(19.1)$ & $180(20.8)$ \\
\hline Another hospital & $26(1.8 \%)$ & $24(2.2 \%)$ & $7(2.0 \%)$ & $4(1.1)$ & $7(2.0)$ & $17(2.0)$ & $23(2.7)$ \\
\hline Other & $21(1.5 \%)$ & $24(2.2 \%)$ & 9 (2.5\%) & $2(0.6)$ & $9(2.5)$ & $11(1.3)$ & $23(2.7)$ \\
\hline \multicolumn{8}{|c|}{ Charlson Score, n (\%) } \\
\hline 0 & $582(41.2 \%)$ & $422(39.5 \%)$ & $121(34.0 \%)$ & $127(35.7)$ & $121(34.0)$ & $322(37.2)$ & $336(38.8)$ \\
\hline 1 & $317(22.5 \%)$ & $239(22.4 \%)$ & $70(19.7 \%)$ & $61(17.1)$ & 70 (19.7) & 201 (23.2) & 207 (23.9) \\
\hline $2+$ & $513(36.3 \%)$ & 408 (38.2\%) & $165(46.3 \%)$ & 168 (47.2) & $165(46.3)$ & $343(39.6)$ & 323 (37.3) \\
\hline $\begin{array}{l}\text { Charlson Score, } \\
\text { median (IQR) }\end{array}$ & $1(0-2)$ & $1(0-2)$ & $1(0-3)$ & $1(0-3)$ & $1(0-3)$ & $1(0-3)$ & $1(0-2)$ \\
\hline $\begin{array}{l}\text { Admission SOFA } \\
\text { score, median } \\
\text { (IQR) }\end{array}$ & $6(4-8)$ & $7(5-10)$ & $8(6-11)$ & $8(5-10)$ & $8(6-11)$ & $7(4-9)$ & $7(4-10)$ \\
\hline $\begin{array}{l}\text { Admission } \\
\text { APACHE II score, } \\
\text { median (IQR) }\end{array}$ & $18(13-24)$ & $19(14-25)$ & $23(16-28)$ & $21(16-27)$ & $23(16-28)$ & $19(14-24)$ & $19(13-26)$ \\
\hline $\begin{array}{l}\text { Vasoactive } \\
\text { medications, n (\%) }\end{array}$ & 639 (45.3\%) & 690 (64.5\%) & 245 (68.8\%) & $241(67.7)$ & $245(68.8)$ & $526(60.7)$ & $488(56.4)$ \\
\hline $\begin{array}{l}\text { Continuous renal } \\
\text { replacement } \\
\text { therapy, n (\%) }\end{array}$ & $59(4.2 \%)$ & 78 (7.3\%) & 33 (9.3\%) & $28(7.9)$ & $33(9.3)$ & $52(6.0)$ & $73(8.4)$ \\
\hline
\end{tabular}

online supplemental tables 1 and 2. There was a statistically significant association between fentanyl dominant sedation strategy and ICU (OR 1.50, 95\% CI 1.07 to 2.12)) and 30-day mortality (OR $1.35,95 \%$ CI 1.02 to 1.79 ) ) in propensity score-matched analyses (online supplemental table 3). An additional sensitivity analysis of the same propensity score-matched cohort evaluating sedation strategy dominance for greater than 6 hours can be found in table 4 . This analysis demonstrated a statistically significant association between fentanyl dominant strategies and a composite of delirium or death, ICU mortality, hospital mortality, 30-day mortality, 1-year mortality, hospital LOS and duration of mechanical ventilation.
Figure 2 Propensity score-matched ORs of delirium by dominant sedation strategy prior to first ICDSC assessment. ICDSC, Intensive Care Delirium Screening Checklist. 
Table 2 Sensitivity analyses examining the relationship between delirium and individual sedation agents prior to first ICDSC assessment

\begin{tabular}{|c|c|c|c|c|c|c|c|}
\hline \multirow[b]{2}{*}{$\begin{array}{l}\text { Sedation agent } \\
\text { prior to first ICDSC } \\
\text { assessment }\end{array}$} & \multicolumn{3}{|c|}{ Overall cohort } & \multicolumn{4}{|c|}{ Matched cohorts } \\
\hline & $\begin{array}{l}\text { No of } \\
\text { patients }\end{array}$ & $\begin{array}{l}\text { Ever } \\
\text { delirium, } \\
\text { n (\%) }\end{array}$ & $\begin{array}{l}\text { Adjusted OR (95\% } \\
\text { Cl)* }\end{array}$ & $\begin{array}{l}\text { No of } \\
\text { patients } \\
\text { per group }\end{array}$ & $\begin{array}{l}\text { Ever } \\
\text { delirium for } \\
\text { propofol } \\
\text { patients } \\
\text { from } \\
\text { matched } \\
\text { cohorts, n } \\
(\%)\end{array}$ & $\begin{array}{l}\text { Ever } \\
\text { delirium, n } \\
(\%)\end{array}$ & $\begin{array}{l}\text { Propensity score- } \\
\text { matched OR for } \\
\text { ever delirium (95\% } \\
\mathrm{Cl}) \dagger\end{array}$ \\
\hline Propofol & 887 & $509(57.4)$ & 1.00 (reference group) & N/A & N/A & N/A & $\begin{array}{l}1.00 \text { (reference } \\
\text { group) }\end{array}$ \\
\hline Fentanyl & 158 & $91(57.6)$ & 1.04 (0.71 to 1.52$)$ & 152 & $74(48.7)$ & $87(57.2)$ & 1.41 (0.90 to 2.22$)$ \\
\hline Midazolam & 124 & $77(62.1)$ & 1.11 (0.73 to 1.69$)$ & 122 & $69(56.6)$ & $75(61.5)$ & 1.23 (0.74 to 2.05$)$ \\
\hline Propofol+fentanyl & 854 & $543(63.6)$ & 1.32 (1.06 to 1.65$)$ & 565 & $323(57.2)$ & $347(61.4)$ & 1.19 (0.94 to 1.51$)$ \\
\hline
\end{tabular}

ICDSC, Intensive Care Delirium Screening Checklist; NA, not available.

\section{DISCUSSION}

Sedative strategies may increase the risk of adverse patient complications such as delirium or prolonged mechanical ventilation. We found a midazolam dominant sedation strategy was associated with increased risk of developing delirium, duration of mechanical ventilation, and a composite of delirium and death. Alternatively, fentanyl was associated with multiple detrimental outcomes including an increased risk of delirium, a composite outcome of delirium or death, ICU and hospital LOS and duration of mechanical ventilation.

The association between benzodiazepine-based sedation strategies and delirium has been suggested in prior literature. ${ }^{81718}$ The importance of these findings should not be understated as patients with delirium suffer prolonged hospital stays, an increased risk of mortality and long term cognitive impairment. ${ }^{78}$ Sedation using multiple agents was also associated with increased delirium risk, duration of mechanical ventilation, ICU LOS and hospital LOS. Whether these effects are a direct result from the sedation strategy, the resulting delirium or as a result of other aspects of their critical illness is unclear.

We also reconfirmed the association between midazolam dominant sedation strategies and longer mechanical ventilation but not mortality as reported by Lonardo et al. ${ }^{11}$ The mechanism between the association of benzodiazepines and mortality is unclear, however prolonged mechanical ventilation is a known risk factor for mortality. ${ }^{28}$ A meta-analysis by Ho et al comparing propofol to other sedation strategies did not demonstrate an impact on mortality; however, it did not specifically look at midazolam compared with other benzodiazpines. ${ }^{29}$ The heterogeneity in mortality outcomes may be attributable to variation in sedation depth, as early deep sedation is an independent predictor of delayed time to extubation and

Table 3 Delirium subtype by dominant sedation strategy prior to first ICDSC assessment among patients experiencing delirium for the propensity score-matched cohorts

\section{Dominant sedation strategy \\ Propofol versus fentanyl matched cohort patients experiencing delirium}

\begin{tabular}{|c|c|c|c|c|}
\hline Delirium subtype & Propofol $(n=529)$ & Fentanyl $(n=569)$ & Propofol $(n=228)$ & $\begin{array}{l}\text { Midazolam } \\
(\mathrm{n}=257)\end{array}$ \\
\hline Hyperactive only, n (\%) & 47 (8.9) & $40(7.0)$ & $15(6.6)$ & $25(9.7)$ \\
\hline Hypoactive only, n (\%) & $210(39.7)$ & $228(40.1)$ & $104(45.6)$ & $106(41.2)$ \\
\hline Mixed, n (\%) & $254(48.0)$ & $289(50.8)$ & $103(45.2)$ & $123(47.9)$ \\
\hline $\begin{array}{l}\text { Unable to assess or classify, } \\
\mathrm{n}(\%)\end{array}$ & $18(3.4)$ & $12(2.1)$ & $6(2.6)$ & $3(1.2)$ \\
\hline
\end{tabular}

Propofol versus midazolam matched cohort patients experiencing delirium

ICDSC, Intensive Care Delirium Screening Checklist. 


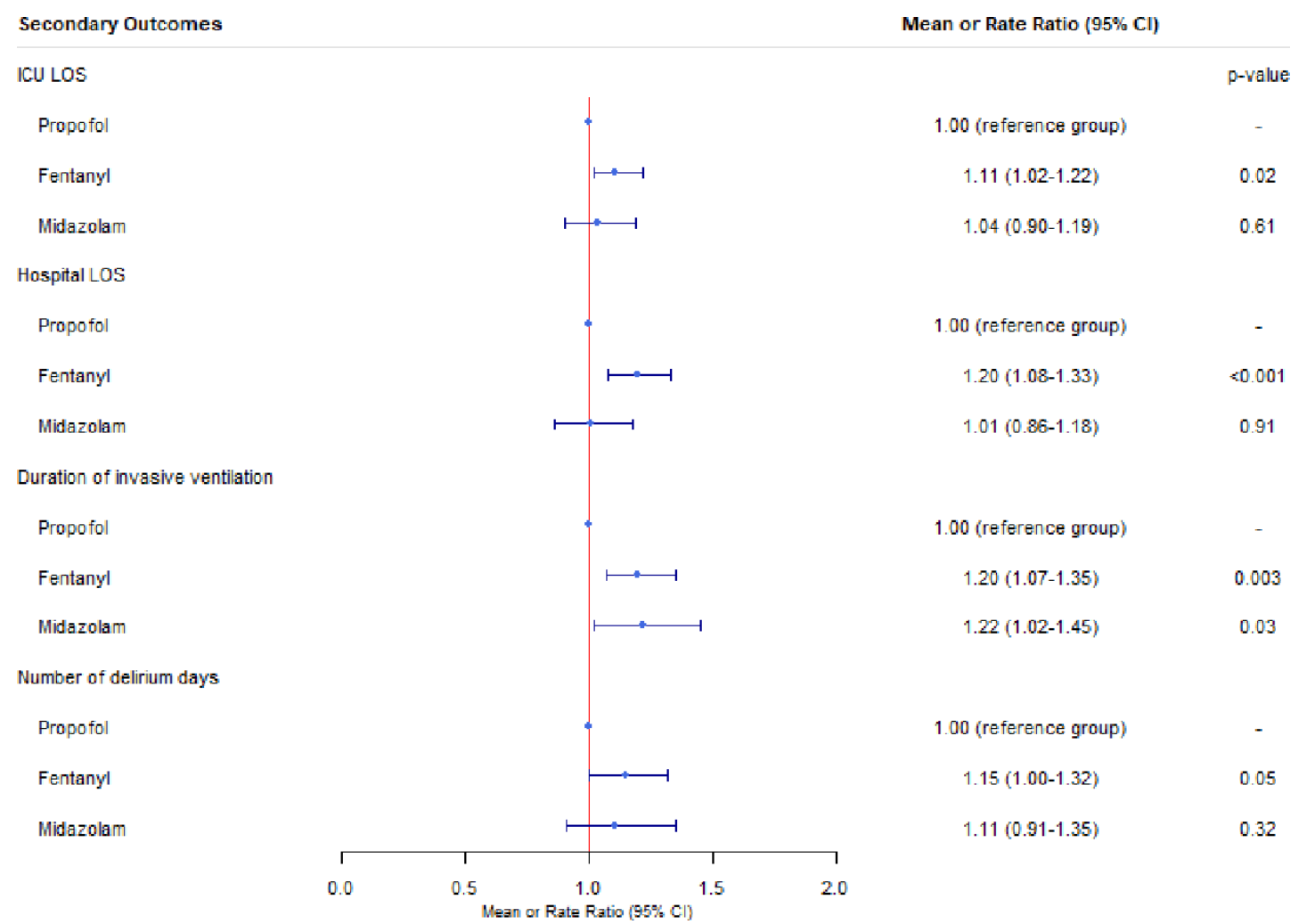

Figure 3 Forest plot of propensity score-matched mean or rate ratios of secondary outcomes and sedation strategy. ICU, intensive care unit; LOS, length of stay.

long term mortality. ${ }^{12}$ Therefore, not only agent choice but also sedation depth might contribute to the variation in mortality risk observed with benzodiazepines.

Sedation with midazolam and fentanyl is often selected for patients with significant haemodynamic instability to avoid the negative ionotropic and vasodilatory effects of propofol. In our study, those receiving midazolam dominant sedation strategies demonstrated significantly higher SOFA scores, APACHE II scores on admission and were more likely to receive vasoactive medications and continuous renal replacement. All of these may impact mortality when unaccounted for and may explain the heterogeneity observed in the literature.$^{30}$ For example, Lonardo et al did not control for the presence of renal replacement which has been associated with a high rate of mortality in critically ill patients. ${ }^{11} 31$ Our use of detailed clinical data for risk adjustment may help explain the differences in mortality compared with prior reports.

A fentanyl dominant sedation strategy was significantly associated with an increased risk of delirium, a composite of delirium or death, ICU LOS, hospital LOS and duration of mechanical ventilation. Prior literature shows associations with delayed extubation when given in the first 48 hours, which supports our findings. ${ }^{12}$ What is unclear is whether our result is a direct effect of fentanyl, an indirect effect from resulting complications of fentanyl use, for example, a pulmonary embolism or pneumonia, or simply an observed association driven by an unidentified confounder. Fentanyl dominant strategies were associated with increased risk of ICU mortality, 30-day mortality, and at hospital discharge but not 1 year. It is difficult to know what to make of these observations. The relationship between fentanyl use and ICU mortality has been incompletely explored in the literature. The mortality risk associated with fentanyl use may be attributable to prolongations in mechanical ventilation. ${ }^{28}$ In our data, the effect of mortality appeared strongest in those receiving only fentanyl and was less robust when used in combination. It is possible those patients who received fentanyl monotherapy were more critically ill. The baseline characteristics of the fentanyl only subgroup revealed these patients that were older, had a higher vasopressor and CRRT use compared with a propofol only but not a midazolam only strategy (online supplemental table S3). However, when fentanyl was the dominant strategy for greater than 6 hours compared with the other two strategies, the association between fentanyl and negative patient centred outcomes was more consistent. This may suggest the detrimental association between fentanyl dominant strategies and patient centred outcomes observed is time dependent. Another possibility could be the immunomodulatory effects of narcotics. The mu-opioid receptor is expressed on macrophages and T-lymphocytes, and chronic administration may increase the risk of bacterial infection. ${ }^{32-34}$ Therefore, large doses of fentanyl may contribute to further immune dysregulation thereby placing critically ill patients at risk of infection. A final possibility is the use of fentanyl in the provision of palliative symptom control, therefore, the mortality association is a marker of this practice. Further 
Table 4 Sensitivity analyses based on those on a single sedation strategy or those whose sedation strategy was dominant for $\geq 6$ hours over the other two strategies

\begin{tabular}{|c|c|c|}
\hline Outcome & $\begin{array}{l}\text { Dominant sedation } \\
\text { strategy }\end{array}$ & $\begin{array}{l}\text { Propensity score- } \\
\text { matched OR, mean } \\
\text { ratio or rate ratio } \\
(95 \% \mathrm{Cl})^{\star}\end{array}$ \\
\hline \multirow[t]{3}{*}{ Delirium ever } & Propofol & 1.00 (reference group) \\
\hline & Fentanyl $(n=476)$ & $1.29(0.99$ to 1.69$)$ \\
\hline & Midazolam $(n=231)$ & 1.64 (1.12 to 2.41$)$ \\
\hline \multirow{3}{*}{$\begin{array}{l}\text { Delirium or } \\
\text { ICU death }\end{array}$} & Propofol & 1.00 (reference group) \\
\hline & Fentanyl $(n=476)$ & $1.38(1.05$ to 1.81$)$ \\
\hline & Midazolam $(n=231)$ & 1.75 (1.18 to 2.60$)$ \\
\hline \multirow[t]{3}{*}{ ICU mortality } & Propofol & 1.00 (reference group) \\
\hline & Fentanyl $(n=476)$ & 1.82 (1.18 to 2.84 ) \\
\hline & Midazolam $(n=231)$ & 1.31 (0.73 to 2.39$)$ \\
\hline \multirow{3}{*}{$\begin{array}{l}\text { Hospital } \\
\text { mortality }\end{array}$} & Propofol & 1.00 (reference group) \\
\hline & Fentanyl $(\mathrm{n}=476)$ & 1.69 (1.19 to 2.42$)$ \\
\hline & Midazolam $(n=231)$ & 1.50 (0.92 to 2.49$)$ \\
\hline \multirow{3}{*}{$\begin{array}{l}\text { Died within } 30 \\
\text { days of ICU } \\
\text { admission }\end{array}$} & Propofol & 1.00 (reference group) \\
\hline & Fentanyl $(n=476)$ & 1.84 (1.27 to 2.68$)$ \\
\hline & Midazolam $(n=231)$ & 1.14 (0.69 to 1.89$)$ \\
\hline \multirow{3}{*}{$\begin{array}{l}\text { Died within } 1 \\
\text { year of ICU } \\
\text { admission }\end{array}$} & Propofol & 1.00 (reference group) \\
\hline & Fentanyl $(\mathrm{n}=476)$ & $1.38(1.02$ to 1.86$)$ \\
\hline & Midazolam $(n=231)$ & $1.16(0.77$ to 1.76$)$ \\
\hline \multirow{3}{*}{$\begin{array}{l}\text { Died within } 1.5 \\
\text { years of ICU } \\
\text { admission }\end{array}$} & Propofol & 1.00 (reference group) \\
\hline & Fentanyl $(n=476)$ & $1.25(0.94$ to 1.66$)$ \\
\hline & Midazolam $(n=231)$ & 1.25 (0.84 to 1.85$)$ \\
\hline \multirow{3}{*}{$\begin{array}{l}\text { ICU length of } \\
\text { stay, mean } \\
\text { ratio }(95 \% \mathrm{CI})\end{array}$} & Propofol & 1.00 (reference group) \\
\hline & Fentanyl $(\mathrm{n}=476)$ & 1.23 (1.09 to 1.39$)$ \\
\hline & Midazolam $(n=231)$ & $1.01(0.86$ to 1.20$)$ \\
\hline \multirow{3}{*}{$\begin{array}{l}\text { Hospital length } \\
\text { of stay, mean } \\
\text { ratio }(95 \% \mathrm{Cl})\end{array}$} & Propofol & 1.00 (reference group) \\
\hline & Fentanyl $(n=476)$ & $1.31(1.13$ to 1.51$)$ \\
\hline & Midazolam $(n=231)$ & 1.01 (0.83 to 1.22$)$ \\
\hline \multirow{3}{*}{$\begin{array}{l}\text { Duration } \\
\text { of invasive } \\
\text { ventilation, } \\
\text { mean ratio } \\
(95 \% \mathrm{Cl})\end{array}$} & Propofol & 1.00 (reference group) \\
\hline & Fentanyl $(n=476)$ & 1.35 (1.14 to 1.59$)$ \\
\hline & Midazolam $(n=231)$ & $1.17(0.94$ to 1.46$)$ \\
\hline \multirow{3}{*}{$\begin{array}{l}\text { No of delirium } \\
\text { days, rate ratio } \\
(95 \% \mathrm{Cl})\end{array}$} & Propofol & 1.00 (reference group) \\
\hline & Fentanyl $(n=476)$ & 1.19 (0.99 to 1.43$)$ \\
\hline & Midazolam $(n=231)$ & 1.11 (0.85 to 1.44$)$ \\
\hline
\end{tabular}

Bold values demonstrate a statistically signficant result.

*Data presented as ORs unless otherwise indicated. ICU, intensive care unit.

study is required to better delineate the true nature of the association between fentanyl and deleterious patient outcomes in the ICU.
Our studies strength is our large cohort size supported by granular patient detail extracted from a prospectively collected, clinical database representing multiple ICUs and the covariates were rigorously controlled using a propensity matched model. ${ }^{22}$ The multicentre study design provides a pragmatic view of how sedation strategies are used in clinical practice. Limitations of our study include the possibility of confounding bias due to unmeasured impactful covariates or confounding by indication. Patients receiving midazolam dominant strategies were clearly more critically ill compared with those receiving propofol dominant strategies manifest by higher APACHE II scores, greater vasopressor requirements and higher rates of renal replacement. To compensate, we conducted propensity score-matched analyses adjusted for known covariates. Additionally, fentanyl and midazolam are often used concurrently and teasing apart the isolated effects of each medication may be challenging. Adjustment with our statistical model should minimise this effect, however, it is possible that unrecognised confounders which are not accounted for in the model could introduce unrecognised bias. Randomised controlled trials would better assess this limitation.

Moreover, we focused primarily on the presence or absence of continuous infusions and did not quantify the impact of independent drug boluses. However, this effect would lessen the association with our primary outcome suggesting our observed associations are conservative. Another limitation is the use of drug duration as a surrogate for the impact of the sedation strategy rather than in vivo plasma concentrations. Patient factors may impact midazolam metabolism due to differences in age, hepatic or renal dysfunction or coadministration of medications with similar metabolic pathways. ${ }^{35-37}$ Finally, the definition of dominant sedation strategy based on longest duration of infusion prior to first ICDSC may be considered arbitrary. It is also possible that the current definition classifies some patients as having one dominant sedation strategy when multiple infusions were discontinued in a noticeably short time frame. However, defining sedation in the setting of multiple agents has been incompletely explored in the literature, therefore novel definitions are required. Our data closely reflects multiple findings previously reported with both midazolam and fentanyl sedation. Furthermore, when restricted to patients who received a dominant sedation strategy for greater than 6 hours, the association between fentanyl dominant strategies and negative patient outcomes was more apparent. This reduces the possibility our findings are pure chance. When thresholds for longer durations of sedation dominance were used, the effects became inconsistent, however, may be secondary to the effects of statistical analysis on progressively smaller populations.

\section{CONCLUSION}

This multicentre, propensity score-matched cohort study demonstrates a novel association between fentanyl 
dominant sedation strategies and negative outcomes in the ICU. Fentanyl dominant sedation strategies were associated with an increased risk of delirium, a composite of delirium or death, duration of ventilation, ICU LOS and hospital LOS. We also confirmed previous reports including an increased risk of delirium and duration of mechanical ventilation with midazolam dominant sedation strategies. This study highlights the need for additional research to further evaluate potentially negative effects of fentanyl and midazolam-based sedation strategies.

Acknowledgements The authors would like to thank the Hotchkiss Brain institute, the 0'Brien Institute for Public Health, and the University of Calgary Departments of Critical Care, Community Health Sciences and Psychiatry for their on-going support. Moreover, we would like to thank the reviewers and editorial team for their hard work and consideration.

Contributors CC was involved in the concept, study protocol, study oversight, statistical modeling, and all aspects of writing the manuscript. AS and CHL were involved in the statistical modeling and contributed to the methods section of the manuscript. KF, DN, TS and PC were involved in developing the concept, study protocol, study oversight and contributed to the discussion of the manuscript.

Funding The authors have not declared a specific grant for this research from any funding agency in the public, commercial or not-for-profit sectors.

Competing interests None declared.

Patient consent for publication Not required.

Ethics approval This retrospective cohort study was reported in compliance with the Strengthening the Reporting of Observational Studies in Epidemiology (STROBE) statement and approved by the conjoint health research ethics board at the University of Calgary (REB17-0389).

Provenance and peer review Not commissioned; externally peer reviewed.

Data availability statement Deidentified patient data is available on reasonable request. Raw data were generated at the University of Calgary. Derived data supporting the findings of this study are available from the corresponding author CC on request. No additional protocols or statistical analyses are available. Author CC can be contacted through orcid at the following link: https://orcid.org/0000-00023032-1206.

Supplemental material This content has been supplied by the author(s). It has not been vetted by BMJ Publishing Group Limited (BMJ) and may not have been peer-reviewed. Any opinions or recommendations discussed are solely those of the author(s) and are not endorsed by BMJ. BMJ disclaims all liability and responsibility arising from any reliance placed on the content. Where the content includes any translated material, BMJ does not warrant the accuracy and reliability of the translations (including but not limited to local regulations, clinical guidelines, terminology, drug names and drug dosages), and is not responsible for any error and/or omissions arising from translation and adaptation or otherwise.

Open access This is an open access article distributed in accordance with the Creative Commons Attribution Non Commercial (CC BY-NC 4.0) license, which permits others to distribute, remix, adapt, build upon this work non-commercially, and license their derivative works on different terms, provided the original work is properly cited, appropriate credit is given, any changes made indicated, and the use is non-commercial. See: http://creativecommons.org/licenses/by-nc/4.0/.

\section{ORCID iDs}

Colin Casault http://orcid.org/0000-0002-3032-1206

Kirsten Fiest http://orcid.org/0000-0002-7299-6594

\section{REFERENCES}

1 Association AP. Diagnostic and Statistical Manual of Mental Disorders(DSM-5. Arlington, VA: American Psychiatric Association, 2013.

2 Ely EW, Inouye SK, Bernard GR, et al. Delirium in mechanically ventilated patients: validity and reliability of the confusion assessment method for the intensive care unit (CAM-ICU). JAMA 2001;286:2703-10.

3 Dubois MJ, Bergeron N, Dumont M, et al. Delirium in an intensive care unit: a study of risk factors. Intensive Care Med 2001;27:1297-304

4 Pandharipande P, Cotton BA, Shintani A, et al. Prevalence and risk factors for development of delirium in surgical and trauma intensive care unit patients. $J$ Trauma 2008;65:34-41.

5 Girard TD, Kress JP, Fuchs BD, et al. Efficacy and safety of a paired sedation and ventilator weaning protocol for mechanically ventilated patients in intensive care (awakening and breathing controlled trial): a randomised controlled trial. Lancet 2008;371:126-34.

6 Zaal IJ, Devlin JW, Peelen LM, et al. A systematic review of risk factors for delirium in the ICU. Crit Care Med 2015;43:40-7.

7 Thomason JWW, Shintani A, Peterson JF, et al. Intensive care unit delirium is an independent predictor of longer hospital stay: a prospective analysis of 261 non-ventilated patients. Crit Care 2005;9:R375-81.

8 Ely EW, Shintani A, Truman B, et al. Delirium as a predictor of mortality in mechanically ventilated patients in the intensive care unit. JAMA 2004;291:1753-62.

9 Needham DM, Bronskill SE, Calinawan JR, et al. Projected incidence of mechanical ventilation in Ontario to 2026: preparing for the aging baby boomers. Crit Care Med 2005;33:574-9.

10 Jacobs P, Noseworthy TW. National estimates of intensive care utilization and costs: Canada and the United States. Crit Care Med 1990;18:1282-6.

11 Lonardo NW, Mone MC, Nirula R, et al. Propofol is associated with favorable outcomes compared with benzodiazepines in ventilated intensive care unit patients. Am J Respir Crit Care Med 2014;189:1383-94.

12 Shehabi Y, Bellomo R, Reade MC, et al. Early intensive care sedation predicts long-term mortality in ventilated critically ill patients. Am J Respir Crit Care Med 2012;186:724-31.

13 Riker RR, Shehabi Y, Bokesch PM, et al. Dexmedetomidine vs midazolam for sedation of critically ill patients: a randomized trial. JAMA 2009;301:489-99.

14 Barrientos-Vega R, Mar Sánchez-Soria M, Morales-García C, et al. Prolonged sedation of critically ill patients with midazolam or propofol: impact on weaning and costs. Crit Care Med 1997;25:33-40.

15 Aitkenhead AR, Pepperman ML, Willatts SM, et al. Comparison of propofol and midazolam for sedation in critically ill patients. Lancet 1989;2:704-9.

16 Chamorro C, de Latorre FJ, Montero A, et al. Comparative study of propofol versus midazolam in the sedation of critically ill patients: results of a prospective, randomized, multicenter trial. Crit Care Med 1996;24:932-9.

17 Barr J, Fraser GL, Puntillo K, et al. Clinical practice guidelines for the management of pain, agitation, and delirium in adult patients in the intensive care unit. Crit Care Med 2013;41:263-306.

18 Pandharipande P, Shintani A, Peterson J, et al. Lorazepam is an independent risk factor for transitioning to delirium in intensive care unit patients. Anesthesiology 2006;104:21-6.

19 Cammarano WB, Pittet JF, Weitz S, et al. Acute withdrawal syndrome related to the administration of analgesic and sedative medications in adult intensive care unit patients. Crit Care Med 1998;26:676-84.

20 von Elm E, Altman DG, Egger M, et al. The strengthening the reporting of observational studies in epidemiology (STROBE) statement: guidelines for reporting observational studies. Lancet 2007;370:1453-7.

21 Chiasson TC, Manns BJ, Stelfox HT. An economic evaluation of venous thromboembolism prophylaxis strategies in critically ill trauma patients at risk of bleeding. PLOS Med 2009;6:e1000098.

22 Brundin-Mather R, Soo A, Zuege DJ, et al. Secondary EMR data for quality improvement and research: a comparison of manual and electronic data collection from an integrated critical care electronic medical record system. J Crit Care 2018;47:295-301.

23 Stelfox HT, Soo A, Niven DJ, et al. Assessment of the safety of discharging select patients directly home from the intensive care unit: a multicenter population-based cohort study. JAMA Intern Med 2018;178:1390-9.

24 Sessler CN, Gosnell MS, Grap MJ, et al. The Richmond AgitationSedation scale: validity and reliability in adult intensive care unit patients. Am J Respir Crit Care Med 2002;166:1338-44.

25 Bergeron N, Dubois MJ, Dumont M, et al. Intensive care delirium screening checklist: evaluation of a new screening tool. Intensive Care Med 2001;27:859-64.

26 Austin PC. Optimal caliper widths for propensity-score matching when estimating differences in means and differences in proportions in observational studies. Pharm Stat 2011;10:150-61. 
27 Team RC. R: a language and environment for statistical computing, 2018.

28 Feng $\mathrm{Y}$, Amoateng-Adjepong $\mathrm{Y}$, Kaufman D, et al. Age, duration of mechanical ventilation, and outcomes of patients who are critically ill. Chest 2009;136:759-64.

$29 \mathrm{Ho} \mathrm{KM}, \mathrm{Ng}$ JY. The use of propofol for medium and long-term sedation in critically ill adult patients: a meta-analysis. Intensive Care Med 2008;34:1969-79.

30 Soo A, Zuege DJ, Fick GH, et al. Describing organ dysfunction in the intensive care unit: a cohort study of 20,000 patients. Crit Care 2019;23:186.

31 Uchino S, Kellum JA, Bellomo R, et al. Acute renal failure in critically ill patients: a multinational, multicenter study. JAMA 2005;294:813-8.

32 Risdahl JM, Khanna KV, Peterson PK, et al. Opiates and infection. J Neuroimmunol 1998;83:4-18.
33 Roy S, Loh HH. Effects of opioids on the immune system. Neurochem Res 1996;21:1375-86.

34 Roy S, Wang J, Kelschenbach J, et al. Modulation of immune function by morphine: implications for susceptibility to infection. $J$ Neuroimmune Pharmacol 2006;1:77-89.

35 Barr J, Zomorodi K, Bertaccini EJ, et al. A double-blind, randomized comparison of i.v. lorazepam versus midazolam for sedation of ICU patients via a pharmacologic model. Anesthesiology 2001;95:286-98.

36 Swart EL, Zuideveld KP, de Jongh J, et al. Comparative population pharmacokinetics of lorazepam and midazolam during long-term continuous infusion in critically ill patients. Br J Clin Pharmacol 2004;57:135-45.

37 Oldenhof $\mathrm{H}$, de Jong M, Steenhoek A, et al. Clinical pharmacokinetics of midazolam in intensive care patients, a wide interpatient variability? Clin Pharmacol Ther 1988;43:263-9. 